\title{
Is VTE prophylaxis beneficial in upper limb major joint replacement surgery? A Systematic Review.
}

\begin{abstract}
:
Background:

Upper limb arthroplasty is an increasingly used treatment modality for end-stage joint disease of the shoulder, elbow and wrist. While complications have been reported, the risk of venous thromboembolism (VTE) has received less attention when compared to the lower limb. Guidance to aid clinical decision-making remains limited. This review aims to ascertain whether VTE prophylaxis is beneficial after upper limb major joint replacement surgery.
\end{abstract}

\section{Methods:}

A systematic review was performed in April 2019, utilising EMBASE, MEDLINE, Cochrane and Google Scholar. All clinical studies reporting VTE incidence and risk reduction (after prophylaxis) in upper limb joint replacement were included.

\section{Results:}

Twenty-four observational studies were identified. The reported incidence of VTE ranged from $0.2 \%-16 \%$ (weighted mean $0.68 \%$ ) and $0.2 \%-0.8 \%$ (weighted mean $0.49 \%$ ) in shoulder and elbow arthroplasty respectively. No records for wrist arthroplasty were found. In the literature, baseline VTE risk of patients without an operation is reported as $0.5 \%$. 


\section{Discussion:}

There is a lack of good quality evidence regarding the risks and benefits of VTE prophylaxis in upper limb major joint replacement surgery. We recommend further research, ideally formal randomised controlled trials to guide recommendations. Although VTE is rare in upper limb surgery, surgeons should remain vigilant to this possibility. 


\section{Background:}

Venous thromboembolism (VTE) refers to two specific clinical diagnoses, deep vein thrombosis (DVT) and pulmonary embolism (PE) 1. VTE continues to impact significantly on morbidity, mortality and carries an economic burden both in the community and hospital setting ${ }^{1,2}$. A recent population-based cohort study revealed that patients diagnosed with VTE are at highest risk of dying within the first year of diagnosis, but also carry an increased mortality risk for up to 30 years when compared to the general population ${ }^{3}$. It is estimate that VTE complicates 2-3 cases per 1000 hospital admissions and is responsible for $5-10 \%$ of all in-hospital deaths ${ }^{4}$. However, the associated morbidity and mortality may be preventable, with appropriate application of prophylactic methods.

VTE prophylaxis, through mechanical and pharmacological techniques, has been demonstrated to be successful in reducing the frequency of VTE cases by up to $70 \% 5$. Such optimal results may only be achieved via best practice prophylaxis, which involves patient-specific assessment of risk factors and clinical management ${ }^{5}$. VTE prophylaxis, therefore, aims to reduce the incidence of VTE and complications including, postthrombotic syndrome, cardiorespiratory complications and ultimately death 5 . Historically, the use of pharmacological prophylaxis was engrained in routine practice for all inpatients ${ }^{6}$. Expert opinion, however, remains divided, and recent evidence has demonstrated little clinical benefit for use in medical patients compared to surgical patients, leading to appeals for re-evaluation of guidance surrounding the use of pharmacological prophylaxis ${ }^{6}$. For high-risk individuals or if pharmacological prophylaxis is contraindicated, mechanical methods may be employed, such as graduated compression stockings (GCS) ${ }^{7}$. 
Major orthopaedic surgery, including joint replacement surgery, remains a strong risk factor for VTE, impacting on all three of the pathophysiological processes described by Virchow's Triad; through the use of tourniquets and immobilisation affecting circulatory stasis, vascular wall injuries due to surgical limb manipulations and the use of pro-coagulant intra-operative agents, such as polymethylmethacrylate bone cement ${ }^{8}$. Whilst the evidence for the use of VTE prophylaxis in medical patients has been questioned, it remains a mainstay in trauma and orthopaedic surgery ${ }^{6}$. Recent updates to NICE guidance has provided robust recommendations for VTE prophylaxis in lower limb orthopaedic surgery, yet guidance remains limited for upper limb surgery ${ }^{8}$.

Various operations are currently offered routinely in the National Health Service (NHS), from total shoulder to partial wrist arthroplasties, with the total number of operations increasing on a yearly basis according to the National Joint Registry ${ }^{9}$. In the United States, shoulder replacement surgery is projected to increase by over $700 \%$ in the next ten years ${ }^{10}$. Current NICE guidance suggests that VTE prophylaxis is unnecessary in upper limb surgery utilising local or regional anaesthetic techniques ${ }^{11}$. NICE, however, advise consideration of VTE prophylaxis for upper limb surgery lasting over 90 minutes or where their operation is likely to make it difficult for patients to mobilise ${ }^{11}$. Other similar guidance also exists, notably the British Elbow and Shoulder Society guidance for VTE prophylaxis ${ }^{12}$. In an effort to aid further development of guidance on the use of VTE prophylaxis after upper limb joint replacement surgery, a systemic review of the literature was performed. This systematic review aimed to ascertain whether VTE prophylaxis is beneficial in upper limb joint replacement surgery by focussing on 
multiple outcome measures, including VTE incidence and complication rates with and without the use of VTE prophylaxis.

\section{Methods:}

A systematic review was performed in April 2019, utilising the preferred reporting items for systemic reports and meta-analyses (PRISMA) statement as an overall guideline for this study. The review was registered in PROSPERO (CRD42019133486).

The search strategy targeted level three and higher evidence, according to the Oxford Centre for Evidence-Based Medicine ${ }^{13}$. Case reports were excluded. The main outcome measures involved assessment of the incidence and overall risk reduction with VTE prophylaxis in patients who have had major upper limb joint replacement surgery, limited to total shoulder arthroplasty, shoulder hemiarthroplasty, reverse shoulder arthroplasty, distal humeral replacement, total elbow arthroplasty, elbow hemiarthroplasty, total wrist arthroplasty and partial wrist arthroplasty. Secondary outcome measures included assessment of complications after using VTE prophylaxis. Patients who had multiple surgical operations during admission in addition to upper limb joint replacement or presented in a polytrauma context were excluded.

The search strategy was executed in Medline, Embase, Google Scholar and the Cochrane Central Register of Controlled Trials in May 2019 (Supplementary Materials). All identified titles and abstracts were analysed using screening inclusion criteria (Table 1) and if eligible, the full paper was scrutinised. Duplicates were removed. The reference lists of included studies were reviewed to identify additional records. Data on VTE 
incidence after upper limb joint surgery, VTE prophylaxis and complications were extracted. Two authors (MK and ARE) independently performed the search strategy and extracted the relevant data. Disagreements were resolved by discussion with a third author (DF). Data analysis was performed using R software (2019) and meta-analysis performed only if the results were similar in interventions and outcomes across two or more studies. Weighted mean incidence was calculated by extracting data on the number of VTE cases and total procedures performed. Randomized controlled trials were assessed using the Cochrane Risk of Bias tool ${ }^{14}$. Non-randomized comparative studies were assessed using the Quality Assessment Tool For Quantitative Studies, with each paper given a global rating of "good", "fair" or "poor" 15.

\section{Results:}

The literature search yielded 450 articles after duplicate records were removed. Of these, 402 articles were excluded after screening the titles and abstracts. After full text review of the remaining 48 records, 24 articles were included in the systematic review (Figure 1); 20 on shoulder arthroplasty, and four on elbow arthroplasty. No articles were found on wrist arthroplasty. The articles were all observational in study design, with no randomised control trials identified. The majority of included studies were retrospective, with only five designed prospectively. All included studies were level II or III 13 .

\section{Shoulder Arthroplasty}

Twenty included studies relating to VTE following shoulder arthroplasty involved a total of 323,005 patients, with no overlapping datasets (Table 2). The total number of 
procedures was 152,177 total shoulder arthroplasty, 105,347 shoulder hemiarthroplasty, 407 reverse shoulder arthroplasty and 7674 revision arthroplasty (Table 2). Two articles did not provide baseline characteristics to assess the number of each surgical procedure performed 16,17 . These surgical procedures were performed for a range of indications, of which $73 \%$ were due to osteoarthritis, with the remaining procedures due to proximal humeral fractures, inflammatory arthropathy, rotator cuff arthropathy, osteonecrosis and failed primary operations (Table 2). The mean age of patients was 66.5 years.

All included articles reported VTE incidence as a percentage (Table 3). The weighted mean VTE incidence in shoulder arthroplasty across all 20 included articles was $0.68 \%$ (Table 3). The total number of VTE events was 2198 episodes, with 268 PEs, 144 DVTs and the remaining episodes were unspecified. Mortality secondary to VTE was reported in four articles, each reporting a single case from a total of 634 patients $16,18-20$. Other complications including post-thrombotic syndrome and clot extension triggering cardiac involvement were not reported.

VTE risk factors were identified in 10 articles, and included advanced age, obesity, cancer, previous history of VTE and coagulopathy (Table 3). VTE prophylaxis methods were described in only six articles. These included one study that excluded patients with VTE prophylaxis 21 , to mechanical (graduated compression and intermittent pneumatic compression devices) and pharmacological (aspirin and LMWH) methods 20,22-25. Of note, the effects of VTE prophylaxis on overall (VTE) risk reduction or complication rates were not reported and no direct comparisons were made between patients undergoing joint replacement with or without VTE prophylaxis. 


\section{Elbow Arthroplasty}

Four included studies reported on cases of VTE following elbow arthroplasty. These involved a total of 6993 patients (Table 4). The total number of procedures was 6733 total elbow arthroplasty and 260 revision total elbow arthroplasty (with no overlapping datasets). No articles describing elbow hemiarthroplasty or distal humeral replacements were identified. Indications for surgery included osteoarthritis, rheumatoid arthritis or trauma, although two articles did not provide data on the indication for surgery in their patient cohort 26,27 . Three articles reported the age of patients, with the mean age calculated at 58.3 years.

All four included elbow arthroplasty studies reported incidence as a percentage (Table 5). The weighted mean VTE incidence in elbow arthroplasty across the four included articles was $0.49 \%$ (range from $0.2 \%$ to $0.8 \%$ ). The total number of VTE events was 34 , comprising of seven PEs, 25 DVTs and the remaining two episodes unspecified. Mortality secondary to VTE was reported in one article, which described one death occurring from three cases of VTE ${ }^{28}$. No other complications were reported.

VTE risk factors were not identified in any of the four included studies. VTE prophylaxis techniques were reported by one study, which described GCS or intermittent pneumatic compression, and early post-operative ambulation, without the use of pharmacological prophylaxis ${ }^{28}$. Of note, the effects of VTE prophylaxis on overall (VTE) risk reduction or complication rates were not reported and no direct comparisons were made between patients undergoing joint replacement with or without VTE prophylaxis. 


\section{Discussion}

Upper limb joint replacement has been postulated to influence thrombus formation due to its effect on Virchow's triad. Pre-operatively, many patients undergoing upper limb arthroplasty have systemic risk factors predisposing to the development of VTE. These include advanced age in those receiving arthroplasty as a treatment for osteoarthritis or trauma, or patients with inflammatory arthropathies ${ }^{20,24}$. During the intra-operative period, kinking of the axillary vein may occur during humeral positioning, leading to vessel wall injury ${ }^{20}$. This, however, does not occur in elbow or wrist arthroplasty ${ }^{29}$. Chemicals, including acrylic bone cement may also be utilised intra-operatively, which have been shown to produce a hypercoagulative environment ${ }^{8}$. In the post-operative period, the arm may routinely be immobilised in a sling, which may contribute to venous stasis 24 . Also, patients may lose some mobility after surgery, and prolonged sitting may lead to kinking of the femoral veins and gravitational pooling of blood in the lower limb, increasing venous stasis and lower limb DVT 20,24. This may also provide an explanation for the more frequently reported lower limb DVT seen after upper limb joint replacement surgery, compared to upper limb DVT episodes that were only described in two included articles in this systematic review 30,31. Interestingly, this suggests that the pathogenesis of VTE following upper limb joint replacement may be influenced more significantly by systemic factors, rather than local factors such as limb manoeuvring, chemical cement use or post-operative limb positioning.

In the included articles, VTE prophylaxis was not given to most patients, attributed by authors to the overall low incidence of VTE, lack of guidance and possibility of complications secondary to pharmacological prophylaxis. In the six included articles that specified their respective VTE prophylaxis protocol, mechanical prophylaxis was 
most commonly used. However, two authors utilised Aspirin for pharmacological prophylaxis ${ }^{20,25}$. Aspirin has recently been shown to be effective, inexpensive and safe form of VTE prophylaxis following lower limb arthroplasty and has been introduced into national guidance 11,32,33. Otherwise, two authors utilised a LMWH-based VTE prophylaxis protocol in selected 'high-risk' patients ${ }^{23,24}$, reporting a VTE incidence of $0.3 \%$ and $12.3 \%$ respectively. Interestingly, after the implementation of the 2007 NICE guidance advising the prescription of LMWH to all orthopaedic inpatients, there was no significant difference in total VTE events before and after universal use of LMWH ${ }^{23}$. Current national guidance published in 2018 advises a patient-specific analysis of risk factors, benefits and risks of pharmacological prophylaxis by the clinician for every orthopaedic inpatient 11 .

The results of the included studies have demonstrated that although VTE following upper limb arthroplasty may be considered as rare, there remains a significant variability in the described VTE incidence, which ranged from $0.2 \%$ to $16 \%$ (with a weighted mean of $0.68 \%$ ) for shoulder arthroplasty and from $0.2 \%$ to $0.8 \%$ (with a weighted mean of $0.49 \%$ ) for elbow arthroplasty. No studies reporting VTE incidence after wrist arthroplasty were identified. In comparison, baseline VTE risk of patients without an operation is reported as $0.5 \%$ in the literature ${ }^{34}$.

The wide variability documented by these studies may represent differences in diagnostic procedure. Some studies included only symptomatic VTE, whilst the others relied on the use of duplex screening or CT scanning ${ }^{20}$. The latter, employed by 6 included studies, will inevitably result in a higher diagnostic rate. The remaining included articles either did not define their use of imaging in the diagnostic process or 
relied on a clinical diagnosis. The wide variability in VTE incidence may also be compounded by differing patient populations amid the included studies, with 12 studies not reporting specific risk factors for VTE development in their respective patient cohort.

VTE prophylaxis, utilising both mechanical and pharmacological methods, is widely regarded as a standard of care of hip and knee arthroplasty procedures ${ }^{11}$. Although various reports exist, the estimated incidence of VTE in hip and knee arthroplasty exceeds 3\% 35,36. Interestingly, studies have been published recommending that an overall VTE risk of over $3 \%$ is required to outweigh the bleeding risk from pharmacological prophylaxis using LMWH 6,37. Major bleeding has been postulated to occur in 2.5 per 1000 patients prescribed LMWH, with a even higher risk of minor bleeding ${ }^{38}$. Of note, various other risks to the patient occur with use of pharmacological prophylaxis, including heparin-induced thrombocytopenia, skin reactions, thrombocytosis, electrolyte imbalances such as hyperkalaemia and osteoporosis. Taking this into account, the VTE risk associated with shoulder arthroplasty (0.68\%) and elbow arthroplasty $(0.49 \%)$ may be sufficiently low to discourage the use of pharmacological prophylaxis. The risks of mechanical prophylaxis methods, such as GCS, may include discomfort and pressure necrosis if poorly fitted, allergic reactions or worsening of ischaemia in legs with impaired arterial flow ${ }^{39}$. Although data on complications remains scarce for mechanical prophylaxis methods, they are generally assumed to be safe if no absolute contraindication is present ${ }^{39}$. In addition, GCS have been shown to be significantly effective in reducing overall DVT risk in hospitalised orthopaedic patients in a recent Cochrane review ${ }^{40}$. Mechanical methods such as GCS, combined with patient 
education and early post-operative ambulation, may represent a safe, yet effective VTE prophylaxis protocol in upper limb joint replacement surgery.

There are major limitations of the studies included in this systematic review. Due to the lack of a randomised controlled study design, quantifying the overall benefit and complications of VTE prophylaxis in upper limb joint replacement surgery remains difficult. All the studies included within this systematic review were of an observational nature, with data mainly extracted from databases. All included studies were prone to intrinsic differences in study populations (selection bias) and lack of an explicit reporting protocol (reporting bias). Data on the complications of VTE prophylaxis or its absence was poorly documented, including no records of post-thrombotic syndrome, clot extension or cardiac involvement. This may possibly be due to a lack of a suitable follow-up and retrospective design in the majority of the included studies. Most included studies did not report details of their VTE prophylaxis protocol, posing difficulties when attempting to contextualise the reported VTE incidence rates within that defined population. This review was also limited to work published in English, therefore it was not possible to identify the incidence across the worldwide literature.

For upper limb joint replacement surgery, NICE guidelines recommend consideration of VTE prophylaxis in patients undergoing upper limb surgery and who are under general anaesthesia for over 90 minutes, or in patients who may struggle to mobilise postoperatively ${ }^{11}$. NICE also suggest that procedures under local or regional anaesthesia do not require VTE prophylaxis ${ }^{11}$. More comprehensive guidance is required to aid surgeons to minimise VTE risk, but this is currently limited by the available evidence base ${ }^{29}$. 


\section{Conclusion}

The risk of VTE in upper limb joint replacement surgery is variable across differing published articles. However, the mean weighted VTE incidence was found to be $0.68 \%$ and $0.49 \%$ in shoulder and elbow arthroplasty respectively, which compare to a literature reported baseline risk of $0.5 \%$ in people not undergoing an operation. No articles describing VTE risk in wrist arthroplasty were found. Although VTE is rare in upper limb surgery, surgeons should remain vigilant to the possibility, especially in procedures under general anaesthetic lasting greater than 90 minutes or patients who have a prolonged post-operative immobility. All patients undergoing upper limb joint replacement surgery should be formally assessed for VTE and bleeding risk, as per national guidance (NICE). Across all major upper limb joint replacement surgery, surgeons should employ mechanical prophylaxis methods, promote early mobilisation post-operatively, and provide patient education in regards to the symptoms, signs and preventative methods for VTE. Pharmacological prophylaxis may be utilised in patients with significant VTE risk factors, but surgeons must be aware of complications, including a major bleeding risk of $0.25 \%$. All of the included articles within this review were observational in nature. Further research, employing a case-control strategy or prospective randomised trial, is required to quantify the risk-benefit ratio of VTE prophylaxis in upper limb joint replacement surgery. 


\section{References:}

1. Moheimani F, Jackson DE. Venous thromboembolism: classification, risk factors, diagnosis, and management. ISRN Hematol. 2011;2011:124610. doi:10.5402/2011/124610

2. Blann AD, Lip GYH. Venous thromboembolism. BMJ. 2006;332(7535):215-219. doi:10.1136/bmj.332.7535.215

3. Søgaard KK, Schmidt M, Pedersen L, Horváth-Puhó E, Sørensen HT. 30-Year Mortality After Venous Thromboembolism. Circulation. 2014;130(10):829-836. doi:10.1161/CIRCULATIONAHA.114.009107

4. Gibbs H, Fletcher J, Blombery P, Collins R, Wheatley D. Venous thromboembolism prophylaxis guideline implementation is improved by nurse directed feedback and audit. Thromb J. 2011;9(1):7. doi:10.1186/1477-9560-9-7

5. Lau BD, Haut ER. Practices to prevent venous thromboembolism: a brief review. BMJ Qual Saf. 2014;23(3):187-195. doi:10.1136/BMJQS-2012-001782

6. Kotaska A. Venous thromboembolism prophylaxis may cause more harm than benefit: an evidence-based analysis of Canadian and international guidelines. Thromb J. 2018;16(1):25. doi:10.1186/s12959-018-0180-6

7. Barker RC, Marval P. Venous thromboembolism: risks and prevention. Contin Educ Anaesth Crit Care Pain. 2011;11(1):18-23. doi:10.1093/bjaceaccp/mkq044

8. Flevas DA, Megaloikonomos PD, Dimopoulos L, Mitsiokapa E, Koulouvaris P, Mavrogenis AF. Thromboembolism prophylaxis in orthopaedics: an update. EFORT open Rev. 2018;3(4):136-148. doi:10.1302/2058-5241.3.170018

9. National Joint Registry. 15th Annual Report 2018.; 2018. http://www.njrreports.org.uk/Portals/0/PDFdownloads/NJR 15th Annual Report 2018.pdf. 
10. Deore VT, Griffiths E, Monga P. Shoulder arthroplasty-Past, present and future.J Arthrosc Jt Surg. 2018;5(1):3-8. doi:10.1016/J.JAJS.2017.12.001

11. NICE. Venous thromboembolism in over 16s: reducing the risk of hospitalacquired deep vein thrombosis or pulmonary embolism. https://www.nice.org.uk/guidance/ng89/chapter/Recommendations\#riskassessment. Published 2018. Accessed January 28, 2019.

12. British Elbow and Shoulder Society. VTE guidelines for shoulder and elbow surgery. https://www.evidence.nhs.uk/document?id=2187206\&returnUrl=search\%3Fom \%3D\%5B\%7B\%22ety\%22\%3A\%5B\%22Guidance\%22\%5D\%7D\%5D\%26q\%3D shoulder\%2Bday\%2Bcase $\% 2$ Bsurgery $\% 26 s p \% 3 D o n \& q=$ shoulder+day+case + sur gery. Published 2013. Accessed November 27, 2019.

13. CEBM. Levels of Evidence. https://www.cebm.net/2009/06/oxford-centreevidence-based-medicine-levels-evidence-march-2009/. Published 2009. Accessed April 25, 2019.

14. Higgins JPT, Altman DG, Gøtzsche PC, et al. The Cochrane Collaboration's tool for assessing risk of bias in randomised trials. BMJ. 2011;343:d5928. doi:10.1136/bmj.d5928

15. Thomas BH, Ciliska D, Dobbins M, Micucci S. A Process for Systematically Reviewing the Literature: Providing the Research Evidence for Public Health Nursing Interventions. Worldviews Evidence-Based Nurs. 2004;1(3):176-184. doi:10.1111/j.1524-475X.2004.04006.X

16. Wronka KS, Pritchard M, Sinha A. Incidence of symptomatic venous thromboembolism following shoulder surgery. Int Orthop. 2014;38(7):1415-1418. doi:10.1007/s00264-014-2329-7 
17. Craig RS, Lane JCE, Carr AJ, Furniss D, Collins GS, Rees JL. Serious adverse events and lifetime risk of reoperation after elective shoulder replacement: population based cohort study using hospital episode statistics for England. BMJ. 2019;364:298. doi:10.1136/bmj.1298

18. Norris TR, Iannotti JP. Functional outcome after shoulder arthroplasty for primary osteoarthritis: A multicenter study. J Shoulder Elb Surg. 2002;11(2):130135. doi:10.1067/MSE.2002.121146

19. Anjum SN, Butt MS. Treatment of comminuted proximal humerus fractures with shoulder hemiarthroplasty in elderly patients. Acta Orthop Belg. 2005;71(4):388395. http://www.ncbi.nlm.nih.gov/pubmed/16184991. Accessed February 2, 2019.

20. Willis AA, Warren RF, Craig E V., et al. Deep vein thrombosis after reconstructive shoulder arthroplasty: A prospective observational study. J Shoulder Elb Surg. 2009;18(1):100-106. doi:10.1016/J.JSE.2008.07.011

21. Navarro RA, Inacio MCS, Burke MF, Costouros JG, Yian EH. Risk of thromboembolism in shoulder arthroplasty: effect of implant type and traumatic indication. Clin Orthop Relat Res. 2013;471(5):1576-1581. doi:10.1007/s11999013-2829-6

22. Hoxie SC, Sperling JW, Cofield RH. Pulmonary embolism after operative treatment of proximal humeral fractures. J Shoulder Elb Surg. 2007;16(6):782-783. doi:10.1016/J.JSE.2006.12.004

23. Jameson SS, James P, Howcroft DWJ, et al. Venous thromboembolic events are rare after shoulder surgery: analysis of a national database. J Shoulder Elb Surg. 2011;20(5):764-770. doi:10.1016/J.JSE.2010.11.034

24. Koch O, du Plessis A, Olorunju S, McLoughlin H, Le Roux T. Incidence of deep vein 
thrombosis following shoulder replacement surgery: a prospective study. $S A$ Orthop J. 2017;16(4):33-39. doi:10.17159/2309-8309/2017/v16n4a5

25. Tashjian RZ, Lilly DT, Isaacson AM, et al. Incidence of and Risk Factors for Symptomatic Venous Thromboembolism After Shoulder Arthroplasty. Am J Orthop (Belle Mead NJ). 45(6):E379-E385.

http://www.ncbi.nlm.nih.gov/pubmed/27737296. Accessed February 2, 2019.

26. Jenkins PJ, Watts AC, Norwood T, Duckworth AD, Rymaszewski LA, McEachan JE. Total elbow replacement: outcome of 1,146 arthroplasties from the Scottish Arthroplasty Project. Acta Orthop. 2013;84(2):119-123.

doi:10.3109/17453674.2013.784658

27. Krenek L, Farng E, Zingmond D, SooHoo NF. Complication and Revision Rates Following Total Elbow Arthroplasty. J Hand Surg Am. 2011;36(1):68-73. doi:10.1016/j.jhsa.2010.09.036

28. Duncan SFM, Sperling JW, Morrey BF. Prevalence of Pulmonary Embolism After Total Elbow Arthroplasty. J Bone Jt Surg. 2007;89(7):1452. doi:10.2106/JBJS.F.01328

29. Roberts DC, Warwick DJ. Venous thromboembolism following elbow, wrist and hand surgery: a review of the literature and prophylaxis guidelines. J Hand Surg (European Vol. 2014;39(3):306-312. doi:10.1177/1753193412469131

30. Sumant G. Krishnan RJNDHWZB. Humeral Hemiarthroplasty with Biologic Resurfacing of the Glenoid for Glenohumeral Arthritis: Two to Fifteen-year Outcomes. J Bone Jt Surgery-american Vol. 2007;89(4):727-734. https://insights.ovid.com/crossref?an=00004623-200704000-00005. Accessed February 2, 2019.

31. Kusnezov N, Dunn JC, Parada SA, Kilcoyne K, Waterman BR. Clinical Outcomes of 
Anatomical Total Shoulder Arthroplasty in a Young, Active Population. Am J Orthop (Belle Mead NJ). 45(5):E273-82.

http://www.ncbi.nlm.nih.gov/pubmed/27552465. Accessed February 2, 2019.

32. Azboy I, Barrack R, Thomas AM, Haddad FS, Parvizi J. Aspirin and the prevention of venous thromboembolism following total joint arthroplasty: commonly asked questions. Bone Joint J. 2017;99-B(11):1420-1430. doi:10.1302/0301620X.99B11.BJJ-2017-0337.R2

33. Anderson DR, Dunbar M, Murnaghan J, et al. Aspirin or Rivaroxaban for VTE Prophylaxis after Hip or Knee Arthroplasty. N Engl J Med. 2018;378(8):699-707. doi:10.1056/NEJMoa1712746

34. Sweetland S, Green J, Liu B, et al. Duration and magnitude of the postoperative risk of venous thromboembolism in middle aged women: prospective cohort study. BMJ. 2009;339(dec03 1):b4583-b4583. doi:10.1136/bmj.b4583

35. NICE. Apixaban for the Prevention of Venous Thromboembolism in People Undergoing Elective Knee and Hip Replacement Surgery.; 2009. https://www.nice.org.uk/guidance/ta245/documents/venousthromboembolism-apixaban-hip-and-knee-surgery-draft-scope-for-consultationprereferral-september-2009-2. Accessed February 3, 2019.

36. Lee S, Hwang J-I, Kim Y, Yoon PW, Ahn J, Yoo JJ. Venous Thromboembolism Following Hip and Knee Replacement Arthroplasty in Korea: A Nationwide Study Based on Claims Registry. J Korean Med Sci. 2016;31(1):80-88. doi:10.3346/jkms.2016.31.1.80

37. Bahl V, Hu HM, Henke PK, Wakefield TW, Campbell DA, Caprini JA. A Validation Study of a Retrospective Venous Thromboembolism Risk Scoring Method. Ann Surg. 2010;251(2):344-350. doi:10.1097/SLA.0b013e3181b7fca6 
38. van Rein N, Biedermann JS, van der Meer FJM, et al. Major bleeding risks of different low-molecular-weight heparin agents: a cohort study in 12934 patients treated for acute venous thrombosis. J Thromb Haemost. 2017;15(7):1386-1391. doi:10.1111/jth.13715

39. Lim CS, Davies AH. Graduated compression stockings. CMAJ. 2014;186(10):E3918. doi:10.1503/cmaj.131281

40. Sachdeva A, Dalton M, Lees T. Graduated compression stockings for prevention of deep vein thrombosis. Cochrane Database Syst Rev. November 2018. doi:10.1002/14651858.CD001484.pub4

41. John W. Sperling RHC. Pulmonary Embolism Following Shoulder Arthroplasty.J Bone Jt Surgery-american Vol. 2002;84(11):1939-1941. https://insights.ovid.com/crossref?an=00004623-200211000-00005. Accessed February 2, 2019.

42. Lyman S, Sherman S, Carter TI, Bach PB, Mandl LA, Marx RG. Prevalence and risk factors for symptomatic thromboembolic events after shoulder arthroplasty. Clin Orthop Relat Res. 2006;448:152-156. doi:10.1097/01.blo.0000194679.87258.6e

43. Lenarz C, Shishani Y, McCrum C, Nowinski RJ, Edwards TB, Gobezie R. Is Reverse Shoulder Arthroplasty Appropriate for the Treatment of Fractures in the Older Patient?: Early Observations. Clin Orthop Relat Res. 2011;469(12):3324-3331. doi:10.1007/s11999-011-2055-z

44. Farng E, Zingmond D, Krenek L, SooHoo NF. Factors predicting complication rates after primary shoulder arthroplasty. J Shoulder Elb Surg. 2011;20(4):557-563. doi:10.1016/J.JSE.2010.11.005

45. Day JS, Ramsey ML, Lau E, Williams GR. Risk of venous thromboembolism after shoulder arthroplasty in the Medicare population. J Shoulder Elb Surg. 
2015;24(1):98-105. doi:10.1016/J.JSE.2014.09.025

46. Day JS, Ramsey ML, Lau E, Williams GR. Risk of venous thromboembolism after shoulder arthroplasty in the Medicare population. J Shoulder Elb Surg. 2015;24(1):98-105. doi:10.1016/j.jse.2014.09.025

47. Sing DC, Tangtiphaiboontana J, Ma CB, Feeley BT, Zhang AL. Incidence and Risk Factors for Venous Thromboembolic Events After Open Shoulder Surgery. J Shoulder Elb Arthroplast. 2017;1:247154921774024. doi: $10.1177 / 2471549217740241$

48. Belmont PJ, Kusnezov NA, Dunn JC, Bader JO, Kilcoyne K, Waterman BR. Predictors of Hospital Readmission After Total Shoulder Arthroplasty. Orthopedics. 2017;40(1):e1-e10. doi:10.3928/01477447-20160915-06

49. Lovy AJ, Keswani A, Beck C, Dowdell JE, Parsons BO. Risk factors for and timing of adverse events after total shoulder arthroplasty. J Shoulder Elb Surg. 2017;26(6):1003-1010. doi:10.1016/j.jse.2016.10.019

50. Zhou H, Orvets ND, Merlin G. Total Elbow Arthroplasty in the United States: Evaluation of Cost, Patient Demographics, and Complication Rates Repository Citation. Clin Epidemiol Commons. doi:10.4081/or.2016.6113 


\section{Figures and Tables}

Table 1: Inclusion Criteria

\begin{tabular}{|c|c|}
\hline Question & Minimum Criteria \\
\hline Does it address the study question? & $\begin{array}{l}\text { VTE or VTE prophylaxis in upper limb } \\
\text { joint replacement surgery }\end{array}$ \\
\hline Does it address the topic? & Upper limb joint replacement surgery \\
\hline Is it a clinical study? & Yes \\
\hline What is the level of evidence? & Observational study or above \\
\hline $\begin{array}{l}\text { Does it address relevant outcome } \\
\text { measures? }\end{array}$ & $\begin{array}{l}\text { Any of: } \\
\text { - Incidence or prevalence of VTE in } \\
\text { upper limb joint replacement } \\
\text { - } \\
\text { joink reduction of VTE in upper limb } \\
\text { prophylaxis } \\
\text { - Complications associated with or } \\
\text { without the use of VTE prophylaxis }\end{array}$ \\
\hline
\end{tabular}




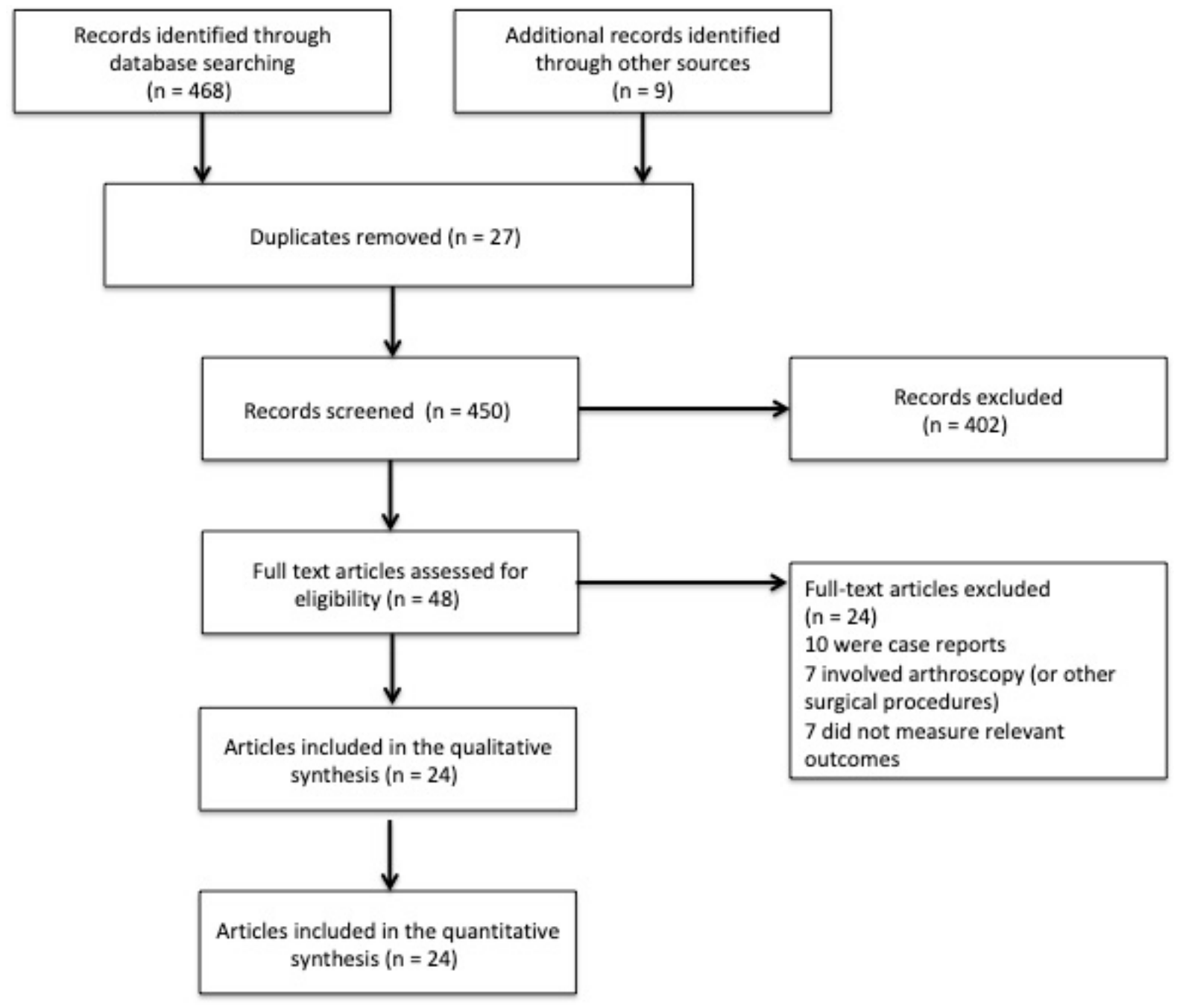

Figure 1: PRISMA diagram showing search and selection method. 
Table 2: Baseline characteristics and summary of included shoulder arthroplasty articles.

\begin{tabular}{|c|c|c|c|c|c|}
\hline Article (year) & Study Design & $\begin{array}{l}\text { Surgical Procedure } \\
\text { (number) }\end{array}$ & Indication for procedure & $\begin{array}{l}\text { Number of } \\
\text { patients (n) }\end{array}$ & Mean Age (years) \\
\hline $\begin{array}{l}\text { Norris and Lannotti (2002) } \\
18\end{array}$ & Prospective & $\begin{array}{l}\text { Total shoulder arthroplasty } \\
\text { (TSA) (133) and shoulder } \\
\text { hemiarthroplasty (SHA) (43) }\end{array}$ & Osteoarthritis $(\mathrm{OA})$ & 160 & 65.1 \\
\hline Sperling and Cofield (2002) & Retrospective & TSA (2308) and SHA (577) & $\begin{array}{l}\text { OA and proximal humerus } \\
(\mathrm{PH}) \text { fractures }\end{array}$ & 2885 & 67 \\
\hline Anjum and Butt (2005) ${ }^{19}$ & Retrospective & SHA (22) & PH fracture & 22 & 77.6 \\
\hline Lyman et al. (2006) ${ }^{42}$ & Retrospective & TSA (4931) and SHA (8828) & $\mathrm{OA}$ and $\mathrm{PH}$ fractures & 13759 & $\begin{array}{l}\text { TSA group } 66.4 \text {, } \\
\text { SHA group } 66.3\end{array}$ \\
\hline Hoxie et al. $(2007)^{22}$ & Retrospective & SHA (37) & PH fractures & 37 & 63.1 \\
\hline Krishan et al. (2007) ${ }^{30}$ & Prospective & SHA (36) & $\mathrm{OA}$ & 34 & 51 \\
\hline Willis et al. (2009) 20 & Prospective & TSA (73) and SHA (27) & $\mathrm{OA}$ and $\mathrm{PH}$ fractures & 100 & 67 \\
\hline Lenarz et al. (2010) ${ }^{43}$ & Retrospective & $\begin{array}{l}\text { Reverse shoulder } \\
\text { arthroplasty (RSA) (30) }\end{array}$ & PH fractures & 30 & 76.7 \\
\hline Farng et al. (2010) ${ }^{44}$ & Retrospective & TSA (6005) and SHA (9283) & $\mathrm{OA}$ and $\mathrm{PH}$ fractures & 15288 & $\begin{array}{l}\text { TSA group } 68.3 \text {, } \\
\text { SHA group } 69.5\end{array}$ \\
\hline Jameson et al. (2010) 23 & Retrospective & TSA (4061), SHA (8297) & $\mathrm{OA}$ and $\mathrm{PH}$ fractures & 12358 & $\begin{array}{l}\text { TSA group 70, SHA } \\
\text { group } 69\end{array}$ \\
\hline Navarro et al. (2013) ${ }^{21}$ & Retrospective & $\begin{array}{l}\text { TSA (1153), SHA (1186) and } \\
\text { RSA (235) }\end{array}$ & $\mathrm{OA}$ and $\mathrm{PH}$ fractures & 2574 & 69.2 \\
\hline Wronka et al. (2014) ${ }^{16}$ & Retrospective & TSA and SHA & $\mathrm{OA}$ and $\mathrm{PH}$ fractures & 352 & Not specified \\
\hline Day et al. (2015) 45 & Retrospective & $\begin{array}{l}\text { TSA (74203) and SHA } \\
(55955)\end{array}$ & Osteoarthritis & 130158 & 72 \\
\hline Kusnezov et al. (2016) ${ }^{31}$ & Prospective & TSA (26) & $\mathrm{OA}$ & 24 & 45.8 \\
\hline Tashjian et al. (2016) ${ }^{25}$ & Retrospective & $\begin{array}{l}\text { TSA (245), SHA (92), RSA } \\
\text { (112) and revision shoulder } \\
\text { arthroplasty ( } 84 \text { ) }\end{array}$ & $\begin{array}{l}\text { OA, rotator cuff arthropathy, } \\
\text { rheumatoid arthritis, failed } \\
\text { primary operation }\end{array}$ & 533 & 65.2 \\
\hline
\end{tabular}




\begin{tabular}{llllll}
\hline Sing et al. (2017) ${ }^{47}$ & Retrospective & $\begin{array}{l}\text { TSA (49686), SHA (20942) } \\
\text { and revision shoulder } \\
\text { arthroplasty (7590) }\end{array}$ & $\begin{array}{l}\text { OA, PH fracture, rotator cuff } \\
\text { arthropathy, failed primary } \\
\text { operations }\end{array}$ & 83391 & 64 \\
\hline Koch et al. (2017) ${ }^{24}$ & Retrospective & $\begin{array}{l}\text { TSA (5), SHA (22) and RSA } \\
(30)\end{array}$ & OA & 57 & 62.6 \\
Belmont et al. (2017) ${ }^{48}$ & Retrospective & TSA (3547) & OA & 3547 & 70.1 \\
Lovy et al. (2017) ${ }^{49}$ & Prospective & TSA (5801) & OA & 5801 & $\begin{array}{l}69.5 \text { (no } \\
\text { complications) } \\
\text { and 73.6 } \\
\text { (complications) }\end{array}$ \\
& & & & & 72.2 \\
Craig et al. (2019) ${ }^{17}$ & Retrospective & $\begin{array}{l}\text { Primary shoulder } \\
\text { replacement (58054) }\end{array}$ & $\begin{array}{l}\text { OA, rotator cuff arthropathy, } \\
\text { inflammatory arthritis, } \\
\text { osteonecrosis }\end{array}$ & 51895 & \\
\hline
\end{tabular}


Table 3: Summary of results and bias assessment of included shoulder arthroplasty articles.

\begin{tabular}{|c|c|c|c|c|c|c|}
\hline Article (year) & VTE Risk Factors & $\begin{array}{l}\text { Prophylaxis } \\
\text { Measures }\end{array}$ & $\begin{array}{l}\text { VTE } \\
\text { Incidence } \\
(\%) \\
\end{array}$ & $\begin{array}{l}\text { Complications and Mortality } \\
\text { (number) }\end{array}$ & $\begin{array}{l}\text { Diagnosis method } \\
\text { (modality) }\end{array}$ & $\begin{array}{l}\text { Bias } \\
\text { Assessment }\end{array}$ \\
\hline $\begin{array}{l}\text { Norris and Lannotti (2002) } \\
18\end{array}$ & Not specified & Not specified & $0.6 \%$ & $\begin{array}{l}\text { PE (1) } \\
\text { Mortality (1) }\end{array}$ & Not specified & Poor \\
\hline Sperling and Cofield (2002) & $\begin{array}{l}\text { Hypertension, } \\
\text { Systemic Lupus } \\
\text { Erythaematosus }\end{array}$ & Not specified & $0.2 \%$ & $\begin{array}{l}\text { PE (5) } \\
\text { Hematoma evacuation (1) }\end{array}$ & $\begin{array}{l}\text { Imaging (ultrasound } \\
\text { and CT) }\end{array}$ & Poor \\
\hline Anjum and Butt (2005) ${ }^{19}$ & Not specified & Not specified & $3.3 \%$ & $\begin{array}{l}\text { PE (1) } \\
\text { Mortality (1) }\end{array}$ & Not specified & Poor \\
\hline Lyman et al. (2006) ${ }^{42}$ & $\begin{array}{l}\text { Cancer, trauma } \\
\text { and elderly age }\end{array}$ & Not specified & $0.7 \%$ & $\begin{array}{l}\text { Lower limb DVT (69) } \\
\text { PE (32) } \\
\text { All Cause Mortality (81) }\end{array}$ & Not specified & Fair \\
\hline Hoxie et al. (2007) $)^{22}$ & $\begin{array}{l}\text { Hypertension, } \\
\text { Systemic Lupus } \\
\text { Erythaematosus }\end{array}$ & $\begin{array}{l}\text { Graded Compression } \\
\text { Stockings and/or } \\
\text { Intermittent } \\
\text { pneumatic } \\
\text { compression (IPC) }\end{array}$ & $10.8 \%$ & $\begin{array}{l}\text { PE (4) } \\
\text { Hematoma evacuation (1) }\end{array}$ & Imaging (CT) & Poor \\
\hline Krishan et al. (2007) ${ }^{30}$ & Not specified & Not specified & $2.9 \%$ & Upper limb DVT (1) & Not specified & Fair \\
\hline Willis et al. (2009) ${ }^{20}$ & $\begin{array}{l}\text { Obesity, elderly } \\
\text { age, past history of } \\
\text { VTE }\end{array}$ & $\begin{array}{l}\text { Post-operative aspirin } \\
\text { and IPC }\end{array}$ & $16 \%$ & $\begin{array}{l}\text { Lower limb DVT (13) } \\
\text { PE (3) } \\
\text { Mortality (1) }\end{array}$ & $\begin{array}{l}\text { Imaging } \\
\text { (ultrasound) }\end{array}$ & Fair \\
\hline Lenarz et al. (2010) ${ }^{43}$ & Not specified & Not specified & $3.3 \%$ & Lower limb DVT (1) & Not specified & Poor \\
\hline Farng et al. (2010) ${ }^{44}$ & $\begin{array}{l}\text { High Charlson } \\
\text { Comorbidity Index }\end{array}$ & Not specified & $0.6 \%$ & $\begin{array}{l}\text { VTE (91) } \\
\text { All Cause Mortality (199) }\end{array}$ & Not specified & Fair \\
\hline Jameson et al. (2010) ${ }^{23}$ & $\begin{array}{l}\text { Elderly age, } \\
\text { obesity, high } \\
\text { Charlson Index }\end{array}$ & $\begin{array}{l}\text { Pharmacological } \\
\text { prophylaxis ( } 4178 \\
\text { patients) }\end{array}$ & $0.3 \%$ & $\begin{array}{l}\text { Lower limb DVT (11) } \\
\text { PE (23) } \\
\text { All Cause Mortality (118) }\end{array}$ & Not specified & Fair \\
\hline Navarro et al. (2013) ${ }^{21}$ & Not specified & $\begin{array}{l}\text { Patients taking } \\
\text { chemoprophylaxis } \\
\text { were excluded }\end{array}$ & $1.01 \%$ & $\begin{array}{l}\text { Lower limb DVT (13) } \\
\text { PE (14) } \\
\text { All cause mortality (13) }\end{array}$ & Clinical & Fair \\
\hline Wronka et al. (2014) ${ }^{16}$ & $\begin{array}{l}\text { No risk factors } \\
\text { identified between } \\
\text { cases of VTE } \\
\text { versus those }\end{array}$ & Not specified & $0.43 \%$ & $\begin{array}{l}\text { Lower limb DVT (6) } \\
\text { PE (4) } \\
\text { Mortality (1) }\end{array}$ & $\begin{array}{l}\text { Imaging (ultrasound } \\
\text { and CT) }\end{array}$ & Poor \\
\hline
\end{tabular}




\begin{tabular}{|c|c|c|c|c|c|c|}
\hline & without. & & & & & \\
\hline Day et al. (2015) ${ }^{46}$ & $\begin{array}{l}\text { Cancer, } \\
\text { coagulopathy, } \\
\text { congestive heart } \\
\text { failure, obesity } \\
\text { and alcohol abuse }\end{array}$ & Not specified & $0.53 \%$ & VTE (695) & Not specified & Fair \\
\hline Kusnezov et al. (2016) ${ }^{31}$ & Not specified & Not specified & $7.7 \%$ & Lower limb DVT (2) & Not specified & Fair \\
\hline Tashjian et al. (2016) ${ }^{25}$ & $\begin{array}{l}\text { Raised Charlson } \\
\text { Index, previous } \\
\text { VTE, diabetes, } \\
\text { anaemia and } \\
\text { obesity }\end{array}$ & Aspirin (125 patients) & $2.6 \%$ & $\begin{array}{l}\text { Upper limb DVT (5) } \\
\text { PE (12) }\end{array}$ & Clinical & Fair \\
\hline Sing et al. (2017) ${ }^{47}$ & $\begin{array}{l}\text { Elderly age, male, } \\
\text { coagulopathy, long } \\
\text { operating time and } \\
\text { obesity }\end{array}$ & $\begin{array}{l}\text { Authors note no data } \\
\text { available }\end{array}$ & $0.26 \%$ & VTE (204) & Not specified & Fair \\
\hline Koch et al. (2017) ${ }^{24}$ & Not specified & $\begin{array}{l}\text { LMWH (18 patients) } \\
\text { Aspirin ( } 81 \mathrm{mg}, 4 \\
\text { patients) } \\
\text { No mechanical } \\
\text { prophylaxis used }\end{array}$ & $12.3 \%$ & $\begin{array}{l}\text { Lower limb DVT ( } 7 \text { ) } \\
\text { LMWH ( } 2 \text { patients developed } \\
\text { DVT) } \\
\text { Aspirin ( } 2 \text { patients developed } \\
\text { DVT) }\end{array}$ & $\begin{array}{l}\text { Imaging } \\
\text { (ultrasound) }\end{array}$ & Poor \\
\hline Belmont et al. (2017) ${ }^{48}$ & Not specified & Not specified & $0.9 \%$ & $\begin{array}{l}\text { Lower limb DVT (16) } \\
\text { PE (13) } \\
\text { All cause mortality (61) }\end{array}$ & Not specified & Fair \\
\hline Lovy et al. (2017) ${ }^{49}$ & $\begin{array}{l}\text { Elderly age, } \\
\text { inflammatory } \\
\text { arthritis, male and } \\
\text { multiple co- } \\
\text { morbidities }\end{array}$ & Not specified & $14 \%$ & $\begin{array}{l}\text { VTE (812) } \\
\text { Dislocation (12) } \\
\text { Post-operative infection (8) } \\
\text { Hematoma (5) } \\
\text { All cause mortality (12) }\end{array}$ & Not specified & Fair \\
\hline Craig et al. (2019) ${ }^{17}$ & $\begin{array}{l}\text { Elderly age, sex } \\
\text { and Charlson } \\
\text { score }\end{array}$ & Not specified & $0.27 \%$ & $\begin{array}{l}\text { VTE (156) } \\
\text { Myocardial infarction (161) } \\
\text { Respiratory tract infection } \\
(1110) \\
\text { All cause mortality (118) }\end{array}$ & Not specified & Fair \\
\hline
\end{tabular}


Table 4: Baseline characteristics and summary of included elbow arthroplasty articles.

\begin{tabular}{|c|c|c|c|c|c|}
\hline Article (year) & Study Design & $\begin{array}{l}\text { Surgical Procedure } \\
\text { (number) }\end{array}$ & Indication for procedure & $\begin{array}{l}\text { Number of } \\
\text { patients (n) }\end{array}$ & Mean Age (years) \\
\hline Duncan et al. (2007) ${ }^{28}$ & Retrospective & $\begin{array}{l}\text { Total elbow arthroplasty } \\
\text { (TEA) (816) and revision } \\
\text { total elbow arthroplasty } \\
\text { (REA) (260) }\end{array}$ & Not specified & 1076 & Not specified \\
\hline Krenek et al. (2011) ${ }^{27}$ & Retrospective & TEA (1625) & $\begin{array}{l}\text { Rheumatoid arthritis and } \\
\text { osteoarthritis }\end{array}$ & 1625 & 56 \\
\hline Jenkins et al. (2012) ${ }^{26}$ & Retrospective & TEA (1146) & $\begin{array}{l}\text { Inflammatory arthropathy, } \\
\text { osteoarthritis and trauma. }\end{array}$ & 1146 & 61 \\
\hline Zhou et al. (2016) 50 & Retrospective & TEA (3146) & Not specified & 3146 & 58 \\
\hline
\end{tabular}

Table 5: Summary of results and bias assessment of included elbow arthroplasty articles.

\begin{tabular}{|c|c|c|c|c|c|c|}
\hline $\begin{array}{l}\begin{array}{l}\text { Article } \\
\text { (year) }\end{array} \\
\end{array}$ & $\begin{array}{l}\text { VTE Risk } \\
\text { Factors } \\
\end{array}$ & $\begin{array}{l}\text { Prophylaxis } \\
\text { Measures }\end{array}$ & $\begin{array}{l}\text { VTE Incidence } \\
(\%)\end{array}$ & $\begin{array}{l}\text { Complications and } \\
\text { Mortality (number) }\end{array}$ & $\begin{array}{l}\text { Diagnosis method } \\
\text { (modality) }\end{array}$ & Bias Assessment \\
\hline $\begin{array}{l}\text { Duncan et } \\
\text { al. (2007) } \\
28\end{array}$ & Not specified & $\begin{array}{l}\text { Graded compression } \\
\text { stockings and IPC. } \\
\text { Post-operative } \\
\text { ambulation }\end{array}$ & $0.28 \%$ & $\begin{array}{l}\text { PE (3) } \\
\text { Mortality (1) }\end{array}$ & Imaging (CTPA) & Poor \\
\hline $\begin{array}{l}\text { Krenek et } \\
\text { al. (2011) } \\
27\end{array}$ & Not specified & Not specified & $0.25 \%$ & $\begin{array}{l}\text { PE }(4) \\
\text { All cause Mortality (10) }\end{array}$ & Not specified & Fair \\
\hline $\begin{array}{l}\text { Jenkins et } \\
\text { al. (2012) } \\
26\end{array}$ & Not specified & Not specified & $\begin{array}{l}0.2 \% \text { at } 90 \text { days } \\
(0.4 \% \text { at one } \\
\text { year })\end{array}$ & $\begin{array}{l}\text { VTE (2) ( } 4 \text { at one year) } \\
\text { Implant infection (22), } \\
\text { dislocation (8) and fracture } \\
(35)\end{array}$ & Not specified & Poor \\
\hline $\begin{array}{l}\text { Zhou et al. } \\
(2016)^{50}\end{array}$ & Not specified & Not specified & $0.8 \%$ & Lower limb DVT(25) & Not specified & Poor \\
\hline
\end{tabular}


Supplementary Material:

Table 1- Search strategy utilised in this systematic review.

\section{Search Strategy}

1. Shoulder replacement

2. Shoulder arthroplasty

3. Distal humeral replacement

4. Elbow arthroplasty

5. Elbow replacement

6. Wrist replacement

7. Wrist arthroplasty

8. VTE

9. Venous thromboembolism

10. DVT

11. Deep vein thrombosis

12. PE

13. Pulmonary embolism

14. VTE prophylaxis

15. Venous thromboembolism prophylaxis

16. Incidence

17. Prevalence

18. Complications

19. Risk

20. 1 AND 8/9/10/11/12/13/14/15/16/17/18/19

21. 2 AND 8/9/10/11/12/13/14/15/16/17/18/19

22. 3 AND 8/9/10/11/12/13/14/15/16/17/18/19

23. 4 AND 8/9/10/11/12/13/14/15/16/17/18/19

24. 5 AND 8/9/10/11/12/13/14/15/16/17/18/19

25. 6 AND 8/9/10/11/12/13/14/15/16/17/18/19

26. 7 AND 8/9/10/11/12/13/14/15/16/17/18/19

27. 1 AND 8/9 AND 16/17/18/19

28. 2 AND 8/9 AND 16/17/18/19

29. 3 AND 8/9 AND 16/17/18/19

30. 4 AND 8/9 AND 16/17/18/19

31. 5 AND 8/9 AND 16/17/18/19

32. 6 AND 8/9 AND 16/17/18/19

33. 7 AND 8/9 AND 16/17/18/19 
Supplementary Material - Quality assessment of included studies

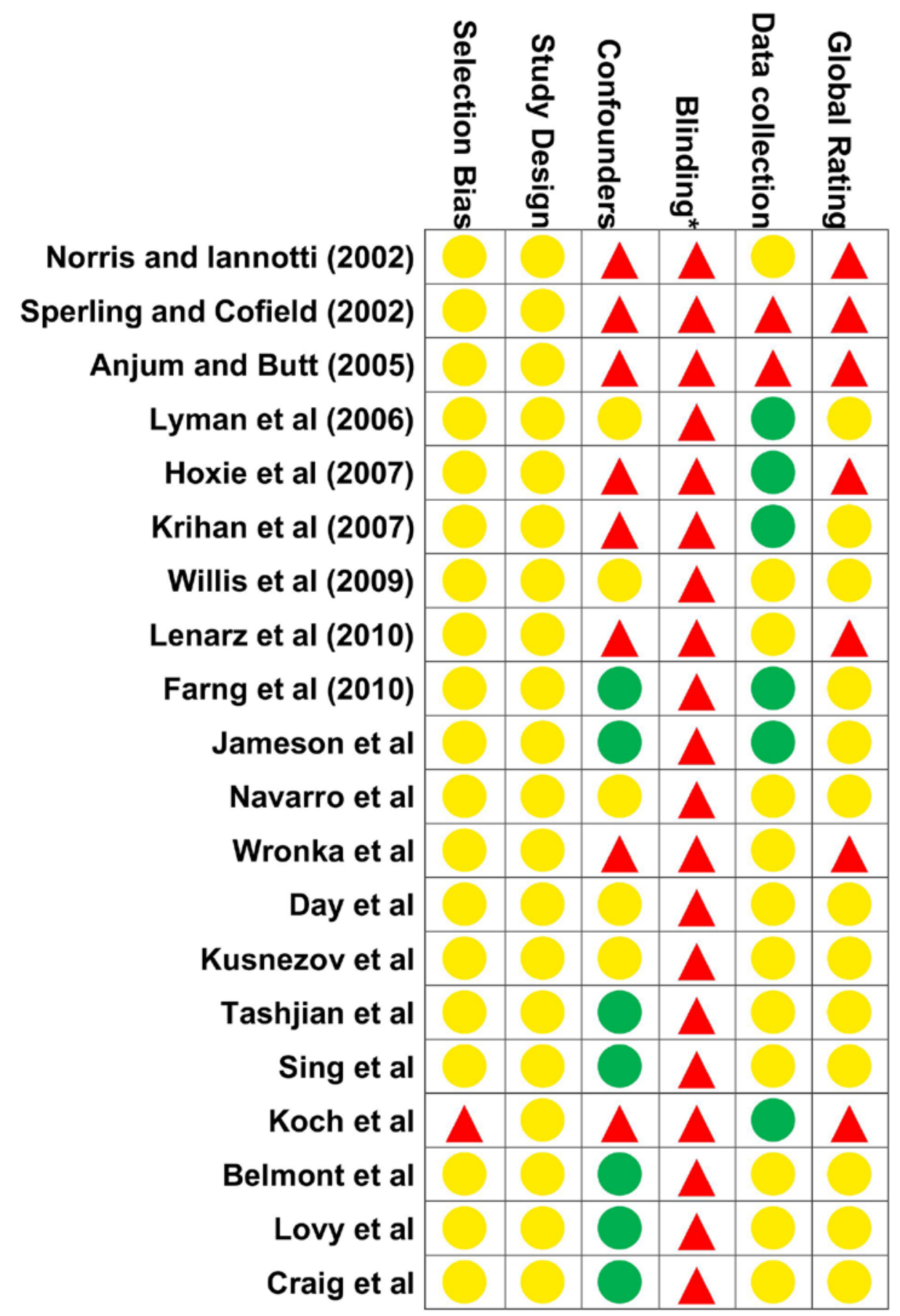

Figure 1- Quality of assessment of shoulder arthroplasty articles. Green circle indicates good articles, yellow circle fair and red triangle poor articles in the specified domains. 


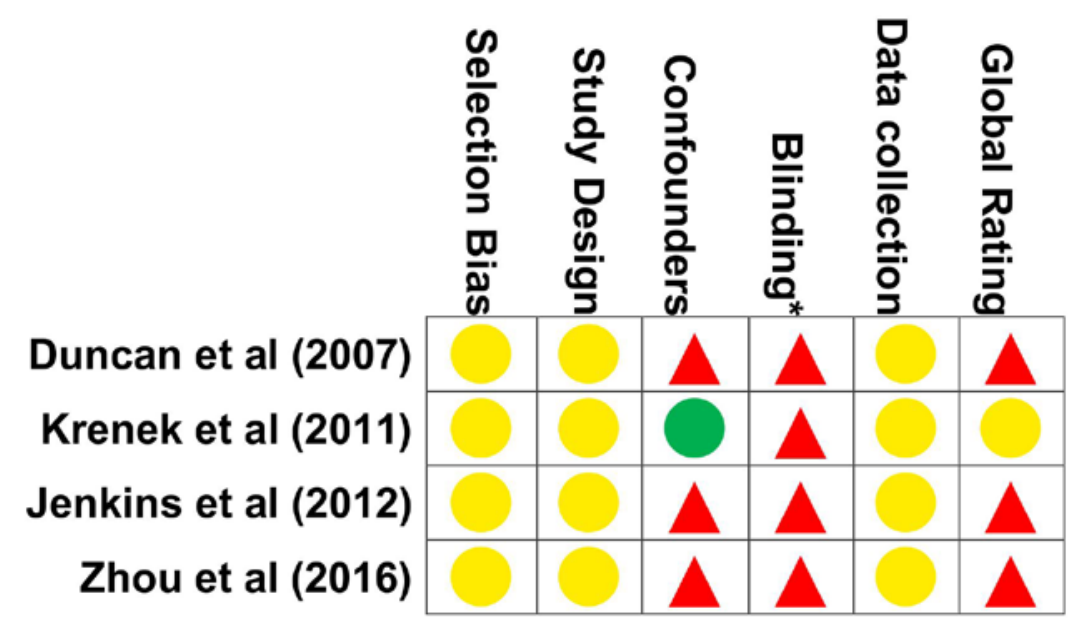

Figure 2- Quality assessment of elbow arthroplasty articles. Green circle indicates strong articles, yellow circle fair and red triangle poor articles in the specified domains.

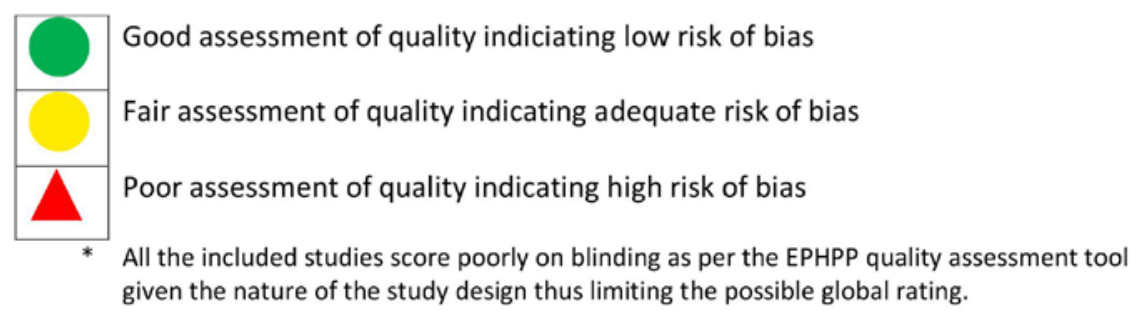

